\title{
Hydroxychloroquine as Oral Antidiabetic Agent During Coronavirus Pandemic
}

\author{
Anirban Majumder* \\ Professor, Department of Endocrinology, KPC Medical College and Hospital, Kolkata, India
}

Received: 09 April, 2020

Accepted: 06 May, 2020

Published: 07 May, 2020

*Corresponding author: Anirban Majumder, MBBS, MD, DM (Endocrinology), Professor, Department of Endocrinology, KPC Medical College and Hospital, Kolkata, 26A, Gariahat Road South, Kolkata - 700031, India, E-mail: dranirbanmazumdar@gmail.com

Keywords: Coronavirus disease; COVID-19; Diabetes; Oral antidiabetic agent; Hydroxychloroquine

https://www.peertechz.com

Check for updates

\begin{abstract}
The coronavirus disease 2019 (COVID-19) is spreading rapidly. Hydroxychloroquine (HCQ), an old drug for treatment of malaria and autoimmune disease with acceptable safety, has shown promising but yet unproven effect against COVID-19 infection. HCQ is an approved agent by the Drug Controller General of India (DCGI) for the therapy of Type 2 Diabetes. In view of the fact that people with diabetes face higher chance of experiencing serious complications from COVID-19, HCQ may have preferential position as an antidiabetic agent during this crisis period.
\end{abstract}

\section{Abbreviations}

WHO: World Health Organization; COVID-19: 2019 Novel Coronavirus; HCQ: Hydroxychloroquine; DCGI: Drug Controller General of India; RSSDI: Research Society for the Study of Diabetes in India; T2DM: Type 2 Diabetes; DISCOVERY : Treatments for COVID-19 in Hospitalized Adults

\section{Introduction}

Coronavirus is a respiratory pathogen and the recent outbreak of Coronavirus disease is caused by the severe acute respiratory syndrome coronavirus 2 (2019 Novel Coronavirus or COVID-19, named by WHO on Feb 11, 2020) [1]. Drastic containment measures to reduce person-to-person transmission of COVID-19 have been implemented to control the current outbreak all over the world. Despite those measures COVID-19 poses a serious global public health threat. People with diabetes face a higher chance of experiencing serious complications and have much higher chance of death than people without diabetes from COVID-19 [2]. The pandemic is particularly threatening for the 463 million estimated diabetes population world wide.

Although there is no specific drug for COVID-19 infection, many broad-spectrum antiviral drugs (oseltamivir, lopinavir, ritonavir and ganciclovir) were used with some success [3]. Interestingly, chloroquine, a well known antimalarial drug, was also found highly effective in controlling COVID-19 infection in vitro [4]. Chloroquine has glucose lowering capacity as well and was first described in a patient with severe insulin resistance in whom it had dramatically reduced insulin requirements [5]. Both chloroquine and hydroxychloroquine (HCQ) are FDAapproved antimalarial drugs. HCQ $400 \mathrm{mg}$ is also approved by the Drug Controller General of India (DCGI) and recommended by the Research Society for the Study of Diabetes in India (RSSDI) in clinical practice recommendations (2017) as add-on therapy after metformin and sulfonylurea in Type 2 Diabetes (T2DM) patients [6].

With the development of many newer, safer and effective antimalarials, chloroquine is no longer a commonly used medication for malaria and hence not widely available all over world. On the other hand, HCQ a derivative of chloroquine, is inexpensive, has immunomodulatory properties, demonstrated to be much less toxic [7], It is widely available to treat many autoimmune diseases (mostly systemic lupus erythematosus and rheumatoid arthritis) and may be a potent candidate to treat infection by COVID-19. Actually, many clinical trial registries are found in Chinese Clinical Trial Registry (http://www.chictr. org.cn) for using HCQ to treat COVID-19. With the spread of the coronavirus across the world, there is an international race to develop effective treatment and HCQ has emerged as one of the frontrunners. In this review, we highlight the importance of preferential use of HCQ as antidiabetic among the susceptible 
diabetic population with a possible add-on benefit in this fatal disease.

\section{Clinical benefit on diabetes control}

HCQ has long been used to treat malaria and many autoimmune diseases (systemic lupus erythematosus and rheumatoid arthritis). It is well known that HCQ can reduce insulin requirements in diabetic subjects and can precipitate hypoglycemic episodes when it is initiated for the treatment of polyarthritis in diabetics requiring insulin or sulfonylurea treatment [8]. Hypoglycemia can also occur in non-diabetic patient treated with HCQ for rheumatoid arthritis [9]. Among a cohort of diabetics, a six month study showed significant 3.3\% decrease in $\mathrm{HbA1C}$ compared to placebo, when HCQ was added to either insulin or glibenclamide in the treatment regimen of T2DM [10]. Similarly, another six month randomized trial among patients with sulfonylurea-refractory T2DM, demonstrated $1.02 \%$ improvement in their $\mathrm{HbA1C}$ when treated with HCQ compared to placebo [11]. HCQ was studied as a third line agent after metformin and SU among uncontrolled diabetic subjects (HbA1C between 7.5-11.0\%) and was found to be well tolerated and effective [12]. Numerous real world evidences are also available regarding the efficacy of HCQ in improving glycemic and lipid parameters in T2DM who are uncontrolled on two OHAs [13].

\section{Mechanism of action of HCQ in improving glucose metabolism}

Numerous studies have shown that HCQ affects insulin metabolism and reduce the plasma glucose level. It enhances insulin secretion [14], alters hepatic insulin metabolism and potentiate insulin action [15]. Being an anti-inflammatory agent, reduction in inflammation might also contribute to reduction in metabolic parameters such as glucose [16]. However, absence of change in markers of inflammation (C-reactive protein and interleukin 6) argue in favour of a direct effect of HCQ on insulin metabolism rather than a consequence of a reduction in inflammation [17]. HCQ improves not only beta cell function and insulin sensitivity but also improves adiponectin levels, an additional novel mediator for the favourable effects observed in glucose metabolism [18].

\section{Clinical benefit on COVID 19}

In vitro, chloroquine appears as a versatile antiviral agent against many RNA viruses [19]. A systemic review on evidences of effectiveness suggests that chloroquine seems to limit the replication of COVID-19 virus in vitro and also safe for longtime clinical use [20]. After reviewing the antiviral mechanisms, efficacy against COVID-19, and pharmacokinetics, chloroquine is proposed as a safe and efficacious agent for protection against COVID-19 [21].

Evidence suggests that both chloroquine and HCQ have the anti-COVID 19 activity. Though the mode of actions of chloroquine and HCQ appear to be distinct in certain aspects, they are principally cytotoxic for the virus. Moreover high concentration of cytokines (cytokine storm) in the plasma of critically ill patients is possibly attenuated by the antiinflammatory action of HCQ [22]. Some in vitro studies suggests that HCQ is more potent than chloroquine in the treatment of Coronavirus [23].

An European clinical trial (DISCOVERY), from the French National Institute of Health and Medical Research (Inserm), will evaluate four experimental treatment options : 1) Remdesivir, 2) Lopinavir and ritonavir in combination, 3) Lopinavir, ritonavir and interferon beta and 4) HCQ. In an unprecedented effort, WHO also launched a large global trial (SOLIDARITY), to collect robust scientific data on these four most promising agents : 1) Remdesivir;, 2) Lopinavir and ritonavir combination, 3) Lopinavir and ritonavir combination plus interferon-beta, 4) Chloroquine and HCQ. Till the trial data is made available, we do not have any evidence based treatment option against this virus.

In the absence of evidence based therapy, it make sense in a situation of a public-health emergency, to use HCQ because of its broad spectrum antiviral activity, and for the possible benefit against COVID 19.

\section{Side effect}

HCQ is not an absolutely safe drug and many issues can arise, from side effects to serious toxicity due to possible interactions with other medications and other underlying health conditions. However, HCQ is an old drug with acceptable safety for use in autoimmune diseases. Undesirable effects of HCQ are particularly severe when the drug is used for longterm therapy. Retinopathy (when maximum daily dosage exceeds $6-6.5 \mathrm{mg} / \mathrm{kg}$ ), deposits in the cornea and disturbances of accommodation are important eye complications. Possibility of complication increases in the presence of renal or hepatic insufficiency. Gastro-intestinal symptoms (e.g. anorexia, diarrhoea, nausea), hyperpigmentation and photodynamic reactions can occur but are not very serious. Neuromyopathy and psychosis can be serious but are rare. Impairment of auditory function is also a rare complication [24]. HCQ-induced cardiomyopathy is also one of the rare but severe complications following prolonged HCQ use [25]. Agranulocytosis is also a rare and infrequently reported complication [26].

\section{Conclusion}

The COVID-19 pandemic is rapidly advancing and diabetic subjects are particularly susceptible to serious complications and very likely to have higher mortality. Development of new medication or prophylaxis will be expensive and time consuming. Pharmaceutical prophylaxis is an established approach to potentially control infectious diseases and repositioning of available drugs should receive priority attention. HCQ is one solution to the urgent public health challenge posed by COVID-19. Being approved by the DCGI for the management of $\mathrm{T} 2 \mathrm{DM}$ patients, we propose to urgently reposition HCQ as a preferential antidiabetic among the susceptible T2DM population with a possible add-on antiviral activity against COVID-19.

Citation: Majumder A (2020) Hydroxychloroquine as Oral Antidiabetic Agent During Coronavirus Pandemic. Glob J Infect Dis Clin Res 6(1): 006-008. 


\section{References}

1. Du Toit (2020) Outbreak of a novel coronavirus. Nat Rev Microbiol 18. Link: https://go.nature.com/35ClyZX

2. Leung $C$ (2020) Clinical features of deaths in the novel coronavirus epidemic in China. Rev Med Virol e2103. Link: https://bit.ly/3beiWD

3. Lu H (2020) Drug treatment options for the 2019-new coronavirus (2019nCoV). Biosci Trends 14: 69-71. Link: https://bit.ly/35BM1b0

4. Wang M, Cao R, Zhang L, Yang X, Liu J, et al. (2020) Remdesivir and chloroquine effectively inhibit the recently emerged novel coronavirus (2019-nCoV) in vitro. Cell Res 30: 269-271. Link: https://bit.ly/2Sli2sO

5. Blazar BR, Whitley CB, Kitabchi AE, Tsai MY, Santiago J, et al. (1984) In vivo chloroquine-induced inhibition of insulin degradation in a diabetic patient with severe insulin resistance. Diabetes 33: 1133-1137. Link: https://bit.ly/2L6dnwz

6. Kumar A, Prakash AS (2019) Effectiveness and Safety of Hydroxychloroquine compared to Teneligliptin in uncontrolled T2DM patients as add-on therapy. Journal of the ASEAN Federation of Endocrine Societies 34: 87. Link: https://bit.ly/3dsxcKN

7. McChesney EW (1983) Animal toxicity and pharmacokinetics of hydroxychloroquine sulfate. Am J Med 75: 11-18. Link: https://bit.ly/2xDHbNU

8. Shojania K, Koehler BE, Elliott T (1999) Hypoglycemia induced by hydroxychloroquine in a type II diabetic treated for polyarthritis. J Rheumatol 26: 195-196. Link: https://bit.ly/3c9WTzm

9. Cansu DU, Korkmaz C (2008) Hypoglycaemia induced by hydroxychloroquine in a non-diabetic patient treated for RA. Rheumatology 47: 378-379. Link: https://bit.ly/2YJ4L74

10. Quatraro A, Consoli G, Magno M, Caretta F, Nardozza A, et al. (1990) Hydroxychloroquine in decompensated, treatment-refractory noninsulindependent diabetes mellitus. A new job for an old drug?. Ann Intern Med 112 678-681. Link: https://bit.ly/35B5qJk

11. Gerstein HC, Thorpe KE, Taylor DW, Haynes RB (2002) The effectiveness of hydroxychloroquine in patients with type 2 diabetes mellitus who are refractory to sulfonylureas--a randomized trial. Diabetes Res Clin Pract 55 209-219. Link: https://bit.ly/2WbYWNG

12. Hsia SH, Duran P, Lee ML, Davidson MB (2020) Randomized controlled trial comparing hydroxychloroquine with pioglitazone as third-line agents in type 2 diabetic patients failing metformin plus a sulfonylurea: A pilot study. $J$ Diabetes 12: 91-94. Link: https://bit.ly/2YDi5tL

13. Purkait I, Pareek A, Panneerselvam A, Mukhopadhyay MK, Kumar S, et al. (2019) 1189-P: Effectiveness of Hydroxychloroquine (HCQ) $400 \mathrm{mg}$ in Uncontrolled T2D Patients on Dual Therapy of Metformin and Sulfonylurea: A Real-World Experience in India. Diabetes 68. Link: https://bit.ly/35BoWFy

14. Asamoah KA, Robb DA, Furman BL (1990) Chronic chloroquine treatment enhances insulin release in rats. Diabetes Res Clin Pract 9: 273-278. Link: https://bit.ly/3frEEHW

15. Powrie JK, Smith GD, Shojaee-Moradie F, Sönksen PH, Jones RH (1991) Mode of action of chloroquine in patients with non-insulin-dependent diabetes mellitus. Am J Physiol 260: E897-904. Link: https://bit.ly/2zhkujf

16. Fox RI (1993) Mechanism of action of hydroxychloroquine as an antirheumatic drug. Semin Arthritis Rheum. 23: 82-91. Link: https://bit.ly/35CEWqM

17. Mercer E, Rekedal L, Garg R, Lu B, Massarotti EM, et al. (2012)
Hydroxychloroquine improves insulin sensitivity in obese non-diabetic individuals. Arthritis Res Ther 14: R135. Link: https://bit.ly/3bhViqd

18. Wasko MC, McClure CK, Kelsey SF, Huber K, Orchard T, et al. (2015) Antidiabetogenic effects of hydroxychloroquine on insulin sensitivity and beta cell function: a randomised trial. Diabetologia 58: 2336-2343. Link: https://bit.ly/3cnSMjz

19. Devaux CA, Rolain JM, Colson P, Raoult D (2020) New insights on the antiviral effects of chloroquine against coronavirus: what to expect for COVID-19? Int J Antimicrob Agents 105938. Link: https://bit.ly/2WxYCrM

20. Cortegiani A, Ingoglia G, Ippolito M, Giarratano A, Einav S (2020) A systematic review on the efficacy and safety of chloroquine for the treatment of COVID-19. J Crit Care Pii: S0883-9441(20)30390-7. Link: https://bit.ly/2YFXZPx

21. Chang R, Sun W (2020) Repositioning Chloroquine as Ideal Antiviral Prophylactic against COVID-19 - Time is Now. Preprints. Link: https://bit.ly/2YHOv6u

22. Liu J, Cao R, Xu M, Wang X, Zhang H, et al. (2020) Hydroxychloroquine, a less toxic derivative of chloroquine, is effective in inhibiting SARS-CoV-2 infection in vitro. Cell Discov 6: 16. Link: https://bit.ly/2YGhZla

23. Yao X, Ye F, Zhang M, Cui C, Huang B, et al. (2020) In Vitro Antiviral Activity and Projection of Optimized Dosing Design of Hydroxychloroquine for the Treatment of Severe Acute Respiratory Syndrome Coronavirus 2 (SARSCoV-2). Clin Infect Dis Link: https://bit.ly/2YBKgt4

24. Ochsendorf FR, Runne U (1991) Chloroquin und Hydroxychloroquin Nebenwirkungsprofil wichtiger Therapeutika [Chloroquine and hydroxychloroquine: side effect profile of important therapeutic drugs. Hautarzt 42: 140-146

25. Zhao H, Wald J, Palmer M, Han Y (2018) Hydroxychloroquine-induced cardiomyopathy and heart failure in twins. J Thorac Dis 10: E70-E73. Link: https://bit.ly/2SJIrHR

26. Sames E, Paterson H, Li C (2016) Hydroxychloroquine-induced agranulocytosis in a patient with long-term rheumatoid arthritis. Eur J Rheumatol 3: 91-92. Link: https://bit.ly/2L6g1T3

\section{Discover a bigger Impact and Visibility of your article publication with}

\section{Peertechz Publications}

\section{Highlights}

* Signatory publisher of ORCID

* Signatory Publisher of DORA (San Francisco Declaration on Research Assessment)

* Articles archived in worlds' renowned service providers such as Portico, CNKI, AGRIS, TDNet, Base (Bielefeld University Library), CrossRef, Scilit, J-Gate etc.

* Journals indexed in ICMJE, SHERPA/ROMEO, Google Scholar etc.

- OAI-PMH (Open Archives Initiative Protocol for Metadata Harvesting)

* Dedicated Editorial Board for every journal

* Accurate and rapid peer-review process

* Increased citations of published articles through promotions

- Reduced timeline for article publication

Submit your articles and experience a new surge in publication services (https://www.peertechz.com/submission).

Peertechz journals wishes everlasting success in your every endeavours.

Copyright: @ 2020 Majumder A. This is an open-access article distributed under the terms of the Creative Commons Attribution License, which permits unrestricted use distribution, and reproduction in any medium, provided the original author and source are credited.

Citation: Majumder A (2020) Hydroxychloroquine as Oral Antidiabetic Agent During Coronavirus Pandemic. Glob J Infect Dis Clin Res 6(1): 006-008. DOI: https://doi.org/10.17352/2455-5363.000027 